\title{
A FRATERNIDADE COMO LEI NATURAL DA ALTERIDADE: UMA REFLEXÃO DE CHIARA LUBICH SOBRE A RACIONALIDADE PRÁTICA E O BEM COMUM EM TEMPOS DE PANDEMIA
}

\author{
Chiara de Sousa Costa ${ }^{1}$
}

Victor Sales Pinheiro

DOI: https://doi.org/10.47306/978-65-88213-03-2.93-106

Sumário: 1 Introdução; 2 A lei natural da faternidade em Chiara Lubich; 3 A fraternidade como lei da alteridade; 4 A liberdade fraterna como liberdade "in", para o bem comum; 5 A fraternidade como racionalidade prática na ação política; 6 Reflexões sobre a pandemia da covid-19 a partir da lei natural; 7 Considerações finais; Referências.

\section{Introdução}

O presente artigo propõe explicitar a fraternidade como lei da alteridade, entendida como a forma mais premente de manifestação da lei natural enquanto reta consciência do ser humano que o orienta às relações fraternas. Reflexão que tem como âncora o discurso da humanista Chiara Lubich à Câmara Municipal de Trento - Itália, em cotejo com autores associados à filosofia política, particularmente, o jusfilósofo Luis Fernando Barzotto.

Reflete-se sobre a fraternidade como lei da alteridade e como própria da política madura cuja ética e orientação não é um conhecimento dado, apropriável e definitivo, mas acessível enquanto alteridade, na experiência vivenciada na relação com o outro, na ética do coexistir fraterno, e enquanto política, por meio da incessante busca dialética da razão pelas verdades práticas, que, como concebe Aristóteles, são contingentes e variáveis, mesmo quando baseadas em princípios universais.

A fraternidade como ética e como consequente racionalidade política apresenta-se como necessidade, mas também como realidade vivida em alguns espaços, e sob determinadas circunstâncias, evidenciando que dos pilares de uma comunidade política urge desenraizar o individualismo recuperando o verdadeiro sentido de liberdade, apoiado na evidência da interdependência mútua e na busca racional e dialética pela verdade e pela justiça como fundamentos políticos e jurídicos do bem comum de uma sociedade fraterna.

\footnotetext{
${ }^{1}$ Mestranda em Direito na Universidade Federal do Pará (PPGD/UFPA). Pós-graduada (MBA) em Direito Civil e Processo Civil pela FGV. Advogada do Banco da Amazônia. http://lattes.cnpq.br/1232383375631784

2 Professor e pesquisador da Universidade Federal do Pará (UFPA) e do Centro Universitário do Pará (CESUPA). Mestre e Doutor em Filosofia. Coordenador do Grupo de Pesquisa Tradição da Lei Natural (CNPq-Brasil) Área de experiência: Filosofia política, moral e jurídica. Site: www.dialetico.com.br.
} 
Esta investigação ética-política tem em vista oferecer, ao final, considerações acerca de uma contextualização específica: a infecção causada pela COVID-19, declarada como pandemia pela Organização Mundial de Saúde, em 11 de março de 2020, e fatores da enfermidade como, gravidade, facilidade de contágio e o elemento geográfico, considerados presentes, ressaltam tanto a generalização da fragilidade humana quanto a relação de afetação e interdependência entre as pessoas. É um cenário no qual um verdadeiro fundamento ético e político reclamam seu espaço e visibilidade, e a hipótese a ser sustentada é a urgência do reconhecimento da própria humanidade por meio da alteridade imbuída da ética da fraternidade.

\section{A lei natural da fraternidade em Chiara Lubich}

Chiara Lubich, ao discorrer sobre a fraternidade na política para a Câmara Municipal de Trento, em 08 de junho de 2001, expôs duas matrizes de compreensão da fraternidade, a de origem teológica como desígnio divino e a de origem racional procedente da Lei Natural. Assim, para os que têm fé, a fraternidade poderia ser espontaneamente compreendida, pois ela “é exatamente o projeto de Deus para toda a humanidade" (LUBICH, 2003, p. 9), valor depreendido dos livros sagrados de inúmeras das grandes religiões presentes no mundo, e, por outro lado, similarmente, a fraternidade é possível de ser conhecida pela consciência atenta de qualquer homem, mesmo dos que se abstém de uma orientação religiosa, alargando à universalidade o seu conceito e apreensão, pois é um princípio "inscrito no coração de cada homem, em todas pessoas [...] atentas à própria consciência”. (LUBICH, 2003, p. 9).

A fraternidade tem o condão de trazer à luz o ideal de uma comunidade de livres e iguais reunidos entre si em torno de um bem próprio e comum a todos, compondo um forte sentido metafísico; com efeito, a fraternidade não se restringe a um tempo, lugar, pessoa ou circunstância; o fator da igualdade e da liberdade, elementos presentes na relação de alteridade,

provém de uma igual aspiração existente em todos os homens: "a aspiração de amar e ser amado dentro de uma comunidade de irmãos”. (LUBICH, 2003, p. 9).

Esta não é uma tenra constatação, porquanto seus axiomas podem ser confrontados e reunidos ao longo da história do pensamento humano. Para citar um reconhecido filósofo da escolástica, Duns Escoto, segundo a investigação de Bonnie Kent, é dele o entendimento de que a aptidão de amar os outros, não por mera utilidade, nem por mero prazer, mas pelo valor que lhe é inerente, "pertence à liberdade inalienável da vontade humana" (KENT, 2008, p. 298), estendendo essa análise ao seguinte enfrentamento: a de que o caráter de dever moral 
desse mandamento só pode derivar do fato de ser esta uma habilidade própria do ser humano enquanto tal, pois essa capacidade de concluir pela igual reciprocidade no agir, de tratar os outros com igual respeito e com igual consideração, ou, ainda, do mesmo modo como gostaria de ser tratado ${ }^{3}$, é um preceito que corresponde à capacidade de poder assim agir, isto é, de ser uma habilidade inerentemente humana, decorrente da razão natural, independente de uma afirmação de fé. E como evidência comprovadora desse argumento, Kent traz a reflexão de Escoto sobre "a disposição que os pagãos têm para morrer em batalha pelo bem de seus países" (KENT, 2008, p. 298) ao que é possível acrescentar a recorrente estratégia de guerra de reunir em agrupamentos os mesmos soldados para utilizar a amizade como um artifício à coragem.

Seguir a consciência e obedecê-la implica uma relação de empatia com os outros, uma atitude de benevolência estendida inclusive àqueles que pertencem a outras culturas, como de fato sugere desde o senso comum - que nomeia de humano o ato solidário, exaltando o altruísta, e nomeia de desumano o ato despido de qualquer benevolência, da qual a insensibilidade ante a dor alheia é condenável moralmente e, por vezes, legalmente - à respeitada filosofia clássica de Tomás de Aquino para quem "homo naturaliter est omni homini amicus" (AQUINO, II-II, v. VII, q. 157, a. 3), sendo intrigante o fato de que não obstante a natureza amiga do homem, ela não se dá de forma natural, isto é, é necessária uma construção de direcionamento voltado para um fim - telos. Com efeito, essa característica iminentemente humana da amizade e do seu invés, a inimizade, é o tema da filosofia política desde que o homem passou a indagar sobre os porquês da própria existência e da melhor forma de conviver.

De fato, é a amizade, segundo Lubich, retomando as lições de Aristóteles, o liame político que responde à pergunta "o que faz de nós cidadãos? ”. O laço político consubstanciado na concórdia que impele todo e qualquer cidadão a abdicar do proveito próprio imediato em vista de trabalhar para obtê-lo com a participação de todos os outros, porque para Aristóteles "a amizade política cria um corpo político que ultrapassa a esfera da utilidade material e alcança a dimensão do bem" (LUBICH, 2003, p. 15), tendo a política um caráter arquitetônico que agrega como um compromisso para o bem comum a contribuição de todos. É próprio da política seu caráter ético a compelir todos a viver com Justiça, compromisso assegurado pelo laço político da amizade política.

\footnotetext{
${ }^{3} \mathrm{O}$ argumento de Escoto pode ser reforçado comparando com o pensamento que o sucedeu em quatro séculos, do proeminente filósofo do modernismo, Emanuel Kant, cuja obrigatoriedade moral da regra de ouro pode se ver refletida em um dos seus imperativos categóricos: aja somente de acordo com a máxima pela qual você pode ao mesmo tempo querer que se torne uma lei universal.
} 
Desta racionalidade, segue-se como um destaque do pensamento de Lubich: a fraternidade como "o fruto maduro do percurso multimilenar da política, a alma para encarar os problemas de hoje" (LUBICH, 2003, p. 12), isto é, a fraternidade se apresenta própria da política refletida, enquanto encontro com o seu dever ser, próprio da imanência humana e do seu amadurecimento, não como uma contribuição externa, como um conceito filosófico a acrescer à práxis política. A política madura para Lubich é essencialmente fraterna, e neste sentido vale trazer a contextualização de Barzotto:

a sociedade fraterna só pode ocorrer quando, na realidade histórica, foram abolidos
todos os tipos de hierarquia ilegítimas que violam a igualdade, foram removidos os
obstáculos à liberdade das pessoas e todos se consideram membros de uma
comunidade na qual vigora a responsabilidade recíproca. (BARZOTTO, 2018, p. 43).

A possibilidade de alcance desta sociedade fraterna, cujo direcionamento é essencialmente político, é ressaltada por Lubich sob o enfoque da alteridade, enquanto o experenciar da fraternidade, uma ética comum manifesta nas relações como reflexo da autoconsciência e, por conseguinte, como compromisso político uma vez que, como confirma Prados, "o político é a pergunta radical acerca da ordem da sociedade" (PRADOS, 2006, p. 192). Assim, diante da pergunta sobre o fim da comunidade, sobre o bem perseguido nas relações, nas pequenas e grandes associações, o ser fraterno é a resposta coerente sobre o que é ser humano.

\section{A fraternidade como lei da alteridade}

Sustentou-se, com o apoio do pensamento de Lubich, ser a lei natural a reta consciência do ser humano que o orienta às relações fraternas; fraternidade que é própria da política, cujos meios de alcance não são como algo dado e apropriável, mas unicamente acessível enquanto política que tem a fraternidade como o horizonte da cidade. Neste ponto, desdobra-se uma decorrência do raciocínio desenvolvido e uma dificuldade: o acesso a esta lei natural, que se revela fraternal, é de igual modo tão enigmática quanto profunda e obscura é a própria humanidade. A resposta sobre o que é fraternidade coincide, de algum modo, sobre o que é ser humano.

Se o ser humano é essencialmente fraternal, a evidência desta realidade desafia a apreensão da própria humanidade, trata-se de descobrir o que se é para que a prática reflita a essência ontológica. A universitas homini nos revela os aspectos comuns acerca da universalidade ontológica - a physys - mas não revela a universalidade moral de uma comunidade e seus respectivos bens, o que pode ser ilustrado pela reflexão da liberdade 
enquanto relação ontologia-ética, porquanto da afirmação de que todo ser humano nasce livre, e que a liberdade lhe é inerente, não se traduz que este o seja efetivamente, posto que a liberdade é carregada de fatores internos (morais, como a escravidão do homem vicioso preso aos seus maus hábitos) e fatores externos (decorrente da escassez de oportunidade e restrição à autonomia, causada pela pobreza, pela falta liberdade política ou civil etc). O ser livre, portanto, ajuda-nos a exemplificar a relação entre a ontologia do nascer livre, por um lado, e o ser livre no plano ético, por outro, ou seja, do dado de que todo o homem é ontologicamente pessoa, não decorre que todos sejam pessoas no plano ético.

Com efeito, para Barzotto, a identidade humana, do ser humano como partícipe da comunidade humana, funciona como referência que se manifesta de três modos: como razão, como natureza (humana) e como alteridade - na relação estabelecida com outro humano, na experiência do existir do outro. Diz o autor que "em cada um desses modos [...] a lei natural é experimentada e conhecida de modo distinto." (BARZOTTO, 2017, p. 123).

Pode-se inferir, como evidenciado em Lubich, a fraternidade como manifestação da lei natural nas relações interpessoais, no aspecto relacional do ser humano, de modo a concluirse como lei da fraternidade a lei que rege as relações humanas - a mais premente das formas de manifestações, posto que é o princípio primeiro da lei natural, porque a experiência do dever em relação ao outro parte antes da experiência do outro enquanto pessoa tanto quanto da pessoa em $\mathrm{si}^{4}$

Aludindo aos termos fraternidade e humanismo, Maria Voce ${ }^{5}$ enfatiza o vínculo coerente desses vocábulos e que a recuperação da significação que trazem é de especial relevância para o momento histórico atual convergindo com o pensamento e exortação do atual sumo Pontífice de que urge elucidar a antropologia do encontro - um ethos ${ }^{6}$ que deve ser formado a partir da saída ao encontro do outro, até os mais recônditos espaços do mundo onde

\footnotetext{
${ }^{4} \mathrm{O}$ tema da pessoa enquanto reconhecimento da existência do outro é captada por diversas perspectivas filosóficas. Mesmo autores distantes das conclusões da tradição tomista, como Marx e Heidegger, por exemplo, trazem interessantes pontos de reflexão a respeito. Marx expõe a seguinte percep̧̧ão: "Como o ser humano não vem ao mundo com um espelho, o ser humano espelha-se primeiramente num outro ser humano. (MARX, 2013 apud BARZOTTO, 2017, p. 128). Por sua vez, Heidegger (2009, p. 146), em chave ontológica e existencial, sobre o tema da apreensão do ser por meio do estar junto ao outro, reflete a possibilidade de ser co-existente, de haver o co-humano, e o eu não se perde no outro, mas manifesta o que é, revela o próprio ser pelo contato com o outro, pelo sair de si: "o ser-aí como tal já se encontra fora junto a..., ele já saiu de si; ou melhor: ele é saindo de si. o próprio ser-aí e esse sair em direção a, perfaz a sua essência.."

${ }^{5}$ A referência é extraída do discurso de Maria Voce atual presidente do Movimento dos Focolares, ao inaugurar a Cátedra Livre Chiara Lubich de Fraternidade e Humanismo, da Unicap e Asces. Em Recife no dia 25 de março de 2014.

${ }^{6}$ Ethos é um vocábulo de origem grega que significa ética, utilizado aqui como ética do corpo social consistente no conjunto de hábitos enraizados que refletem características morais que o definem, funcionando como o espírito animador das práticas, princípios e normas, designando ainda, o modo não proposicional de conhecimento da lei natural, também denominado de conaturalidade.
} 
se encontram periferias existenciais. Trata-se de uma crise não restrita à economia ou a cultura, mas, mais a fundo, "uma crise do ser humano", 7 que é preponderantemente uma crise nas relações, o que gera uma decadência de todo tecido social.

De fato, a relação com o outro atua como manifestação da lei natural explicitando em nós, nossa própria humanidade. Revelando ainda a forma própria que delimita essa relação: a atitude de benevolência. Mas, como dito anteriormente, não obstante ser essa a natureza que vai ao encontro do que é humano, este processo não se dá naturalmente, porquanto a obscuridade da própria humanidade. Na relação com o outro, a configuração da fraternidade exige que os membros da comunidade sejam livres e iguais. Liberdade e igualdade são elementos intrínsecos à natureza humana que demanda o ato de reconhecer.

Sublinha-se, quanto à alteridade e quanto ao reconhecimento da humanidade do outro, que as manifestações da lei natural relacionadas à natureza, à cultura, aos argumentos, somente serão eficazes se tiverem como fundamento a práxis, o que implica a seguinte consideração: o reconhecimento de que o ser humano é por natureza livre e que tem igual dignidade, não advém de declaração ou acordo, mas do reconhecimento de algo que preexiste e independe do próprio ato de reconhecer. Contudo, se obscura é a própria humanidade, o reconhecimento da humanidade do outro necessita de estruturas humanas que convirjam para essa disposição que implica não só no alcance racional, mas que se reflita em atos. Pensar e agir de acordo com o natural reconhecimento da humanidade em todos os seres humanos é facilitado por uma comunidade política, cujo ethos conduza a esta elucidação. Estruturas sociais injustas, marcadamente desiguais, por exemplo, funcionam como muros que não só separam as pessoas em espaços diferentes, mas em humanidades diferentes.

\section{A liberdade fraterna como liberdade "in", para o bem comum}

Sob a ótica fraterna, a liberdade verdadeira é considerada como uma liberdade "in" em oposição a comumente liberdade "de" (liberdade negativa), própria de nossos tempos em que se tem por radicalizada ideias, hábitos e um "ethos" individualista. Liberdade "in” implica laços de pertença na qual a reciprocidade se vincula à liberdade, é com ela associada e não desvinculada porque a liberdade para o desenvolvimento pleno de cada cidadão possui necessário reflexo na comunidade: quanto mais livre é uma determinada pessoa, mais livre é a comunidade a que ela se vincula. Dado que a relação para com o outro é de benevolência, todo

\footnotetext{
${ }^{7}$ Expressão de Maria Voce no discurso mencionado na nota explicativa 5.
} 
dom pessoal é um serviço aos outros. Todo bem individual é um bem do todo, perfaz o bem comum.

Apreende-se das polis gregas, no período em que se vislumbrou uma República democrática e a cidade era vista como um "recinto sagrado", que o povo reunia-se em torno de uma identidade e de uma missão. No entanto, esses laços verdadeiros eram restritos, vividos dentro da comunidade e a exclusão era, de certa forma, institucionalizada, pois alargava o conceito de irracionalidade e de incapacidade às mulheres, crianças e aos que não podiam se expressar. Havia uma cultura do medo ao novo que restringia a vida da fraternidade a uma fraternidade intramuros, somente aos que eram reconhecidos como iguais e, desses, os estrangeiros eram evidentemente excluídos. Mas, ressalte-se, deste contexto, por outro lado, a presença de laços de verdadeira pertença e de cidadania comprometida com o todo; a política, construída por meio dos debates, da deliberação em torno dos meios para atingir fins aos quais cada um sabia-se partícipe e via-se representado.

Por isso, sob o ponto de vista da liberdade, é imprescindível que esta seja uma liberdade "in”, como diferencia Lubich, significando que a verdadeira liberdade é vinculada aos demais, não só por representar um limite ao agir, mas porque a alteridade é reveladora da plena humanidade, o que só é possível quando em torno de fins comuns, no qual o fim último (ainda que contingente frágil e não apropriável) é o amor recíproco.

Comparando e abstraindo a sabedoria da modernidade, Lubich sublinha que o nascimento das cidades tal como conhecemos hoje, de raízes assentadas na associação oriunda da livre escolha de indivíduos, permitiram que fossem configuradas, mais tarde, como cidades multiétnicas, propensas a abraçar o novo, com menos ênfase na tradição, mas focadas no projeto, no porvir, de modo que aspectos da liberdade como criatividade, liberdade de expressão e de iniciativa, puderam encontrar amplo espaço; e, nesse contexto, foi ressaltado um princípio de universalidade a enfatizar a abertura que permite fazer parte da cidade quem quer se comprometa com os fins dessa comunidade inserindo-se na sua vida, participando de suas atividades. Mas ressalta Lubich que a liberdade, posta em grau máximo de valor democrático, imbuída de um indivíduo fundado no auto interesse, desfigura-se numa liberdade "de", isto é, numa liberdade do outro, liberdade considerada como negativa, em contraposição à liberdade “in”, liberdade com um outro dentro de uma comunidade, e este desvínculo afasta qualquer ideal concreto de fraternidade, fazendo com que:

A cidade de hoje corra o risco de não ser mais uma comunidade, mas de se reduzir a um 'aglomerado urbano', no qual cada um, na indiferença de todos, pode dedicar-se aos próprios interesses e, um ou outro, aos próprios negócios. Nesse caso, reina aí uma liberdade negativa, uma liberdade "de" todo vínculo de verdadeira pertença, em 
que o outro não é o irmão, não possui rosto, é apenas um indivíduo. (LUBICH, 2003, p. 13).

Os sentimentos de vínculo, pertencimento, compromisso político, eram o que os mais apaixonados engajadores revolucionários do século XIX tinham receio de perder ao lutarem pela tão sonhada liberdade individual. Um dos mais influentes autores do liberalismo político, Benjamin Constant, para quem a liberdade política configurava-se como poderoso e enérgico meio de aperfeiçoamento dos seres humanos, alertava para o perigo da liberdade moderna caso focasse demasiadamente na busca de interesses particulares, pois teria, como reflexo, a indiferença com os bens da comunidade e a renúncia ao direito de participação política.

O risco de desvirtuamento da liberdade representa mais do que violação da própria liberdade em si. De fato, esses autores de densidade filosófica que fomentaram o liberalismo francês (ao lado de Constant, François Guizot e Alexis de Tocqueville) tinham a clara compreensão de que uma sociedade composta de indivíduos atomizados era um prejuízo para a ansiada liberdade individual, pois a vida política é o sustentáculo dessas liberdades individuais e "a preocupação quase exclusiva com os interesses particulares são alguns dos maiores perigos para a perda da própria liberdade" (CONSTANT, 2019, p. 19), mas percebiam anda mais. Com efeito, o individualismo não permite a formação coordenada da sociedade e a política perde seu caráter arquitetônico, sendo, na verdade, para referir-se à tão utilizada metáfora do navio, uma embarcação à deriva. E, neste direcionamento, uma outra ameaça se perfaz:

Indivíduos isolados e tomados pelo medo e pela desconfiança mútua seriam o substrato ideal para o apelo de um poder supremo que, com punhos de ferro, ergueria um regime autocrático e paternalista, o oposto do ideal de liberdade dos pensadores liberais. (CONSTANT, 2019, p. 15).

Assim, Lubich afirma que resulta da fraternidade, como um dos seus efeitos, uma liberdade que seja verdadeira em contraposição a uma liberdade meramente negativa resultado da exigência de abstenção da atuação do Estado e de qualquer interferência do outro, pois salienta o vínculo entre as pessoas e a reciprocidade de direitos e deveres.

\section{A fraternidade como racionalidade prática na ação política}

Ao enfatizar a urgência de desenraizar o individualismo dos pilares de uma comunidade política para apoiar-se na evidência da interdependência mútua e na busca racional e dialética pela verdade e pela justiça como fundamentos políticos do bem comum, cabem considerações a respeito da racionalidade prática política como alteridade e como o ethos que expresse o êxodo até o outro. 
O ethos de uma comunidade política fraterna exige que o atuar político seja arquitetônico e integrador das ações éticas individuais no sentido tanto de esculpir suas instituições sobre o horizonte hermenêutico que congregue as liberdades individuais para um fim comum, como a de propiciar condições estruturais e culturais que favoreça a fraternidade como prática nas relações entre as pessoas.

Propõem-se que a política, ao invés de ser vista instrumentalmente - como mero processo, resumida a regras de convivência, a um sistema de racionalidade autônoma baseada em critérios legais e objetivos precedentes - seja repensada por meio da racionalidade do agir sob o vínculo da comunidade, como a ação comum prática, cuja natureza não difere substancialmente da ação individual, mas tem para com a ação individual condição recíproca de responsabilidade.

A situação de pandemia mostra-se emblemática para a compreensão do argumento porque traz à tona não só a fragilidade da vida, mas também a necessidade de responsabilidade recíproca de uns para com os outros, isto é, vulnerabilidade e premência de cooperação, pois seria inócua a ação do Estado sem a atividade individual no mesmo sentido de ação. O contexto expõe a racionalidade da fraternidade na qual a ação política, em que pese a base científica com dados colhidos em institutos especializados médicos, estatísticos, sociológicos e econômicos etc, - utiliza tais evidências como subsídio à deliberação dialética para que haja um consenso a ser abraçado pela ação política da comunidade que leva em consideração não só o todo, mas todos.

O combate à pandemia representa assim uma ação comum cuja racionalidade prática é o marco que efetivamente torna possível a ação individual racional. É a partir do consenso acerca do que significa o bem comum, do qual por exemplo, decorreria o isolamento social para o fim de amenização do risco de contágio e sobrecarga do sistema sanitário, é que a ação individual tem um critério para agir. Este exemplo tem o condão de significar que na ausência de uma ação comum, sem que haja uma moralidade prática constituída no seio da comunidade, fica o indivíduo impossibilitado de mensurar a moralidade de sua própria prática, pois sem critérios morais, suas decisões serão guiadas por desejos e sentimentos

Diante dessa base, pode-se inferir que a política não é apenas uma das esferas autônomas da sociedade, resumida a coerção e poder; outro ângulo é perseguido, e para tanto, há a exigência de que o político seja compreendido a partir das "categorias de acción, integración y ethos" (PRADOS, 2006, p. 106), o que viabiliza essa racionalidade como racionalidade prática na ação política. Neste passo, para saber, por exemplo, o que cabe a cada 
um como ação racional, é preciso saber o que fazemos juntos, porquanto sem referência aos fins qualquer debate acerca de uma prática é inviabilizado.

Lubich resolve a necessidade do político de envolver-se na prática da ética fraterna por meio do agir para com o outro sob o prisma da igualdade, isto é, de colocar-se no lugar dele um elemento da fraternidade. De fato, por vezes, o político é percebido como apto a desempenhar papel instrumental e relativista, fundamentado na antropologia do ser auto interessado, desintegrando, desta feita, sob o auspício de neutralidade, o corpo político, redundando num certo distanciamento dos cidadãos entre si e destes com a política (enquanto participação e engajamento) sob o prognóstico da liberdade negativa. Neste rumo, percebe Lubich o perigo de serem os cidadãos como estrangeiros da própria cidade, sem vínculo e sem interesse participativo porque "excluído do tecido social e separado do corpo político, mercê da falta de trabalho, [...] de casa, ou [...] de se cuidar convenientemente" (LUBICH, 2003, p. 12). Acentua Lubich que é por meio do "relacionamento com o Município em suas diversas articulações, que o cidadão desenvolve a gratidão - ou o rancor - pelo conjunto das instituições, inclusive as mais distantes, como o Estado.”. (LUBICH, 2003, p. 12).

A política, com sua função arquitetônica não segue um modelo de governo que se impõe porque há a valorização da participação ativa de todos os membros desviando-se a política dos extremos a que sempre está sujeita: ações paternalistas ou libertárias. ${ }^{8}$

Somente uma política comprometida com uma finalidade clara de fraternidade, revertida em atos conscientes, é capaz de produzir na cidade a verdadeira liberdade porque respeita, sobretudo o vínculo existente entre os cidadãos dessa comunidade. Tal percepção, baseada na antropologia do encontro ${ }^{9}$, ressalta a figura do Município, como ente público próximo do cidadão que conta com a diversidade de dons de cada um voltado ao bem comum, o que significa a inclusão dos bens individuais, pois o bem do outro é para todos e cada um assumido como próprio. Em vista da igualdade, conclui Lubich pela necessidade de condições para a autonomia e expressão da vocação das pessoas e comunidades em prol de uma realização integral a refletir na realização da cidade:

A cidade, assim, não é governada do alto, mas é erguida de baixo, e a política assume a função de pedúnculo que sustenta o florescer das iniciativas pensadas pelos cidadãos

\footnotetext{
${ }^{8}$ Finnis traz um princípio que vai ao encontro deste sentido fraterno da política, o princípio da subsidiariedade, o qual salienta ser um princípio de justiça significando suporte e assistência aos indivíduos e comunidades com o fim de seu desenvolvimento autônomo e livre pois: “A função própria da associação é ajudar os participantes da associação a ajudar a si mesmos, ou, mais precisamente, a constituir-se a si próprios por meio das iniciativas individuais de escolher compromissos e de cumprir esses compromissos por meio de inventividade pessoal e esforço em projetos". (FINNIS, 2007, p. 148).

${ }^{9}$ Baseamo-nos na reflexão pontifícia expressa na Exortação Evangelium Gaudium, do Papa Francisco, explicitado no discurso mencionado na nota explicativa 5, na qual é proposta como fundamento de ação, a antropologia do encontro, como resposta à negação da primazia do ser humano.
} 
ou junto com eles; torna-se um serviço verdadeiro, unificando para o bem comum, os esforços de todos, [...] [na qual] [...]cada um recebe a oportunidade de viver a sua própria vocação e, realizando a si mesmo ajuda o desenvolvimento e o bem da cidade. (LUBICH, 2003, p. 15).

Assim, a fraternidade como horizonte para as dimensões da igualdade e das liberdades individuais representa a razão prática como uma razão dialética que põe em relevo a participação dos cidadãos que se reconhecem livres e iguais em torno de uma comunidade e é esta experiência de alteridade que permite pensar em um bem comum que considere a todos, não só os da mesma comunidade, mas possibilite considerar todos os homens, isto é, "pensar na humanidade inteira em termos políticos" porque:

Da reflexão sobre a cidade nasce, portanto, a reflexão sobre a humanidade [...] porque a cidade é o lugar onde a Fraternidade pode ser vivida concretamente, é o lugar especial onde amadurece o universal que reside em nós, a nossa humanidade. (LUBICH, 2003, p. 16).

Discordamos de uma afirmação específica de Prados de que a amizade e não a fraternidade é o termo adequado para os relacionamentos dentro comunidade política. Nosso contraponto justifica-se porque do termo amizade seria possível decorrer a restrição do reconhecimento da humanidade do outro a pessoas delimitáveis sob alguma característica, o que faz menção à fraternidade intramuros, e não é a esta que este trabalho alude, pois na concepção proposta, fraternidade sectária não consiste uma possível interpretação, mas sua negação. Nos termos de Lubich e Barzotto a fraternidade não decorre necessariamente da teologia, da fé em um Pai comum, mas possível de ser alcançada pela Lei Natural. A fraternidade é apontada como uma metáfora apropriada pela característica de uma comunidade de livres e iguais, o que se estende no seu mais largo alcance à comunidade humana.

\section{Reflexões sobre a pandemia da covid-19 a partir da lei natural}

A lei natural, considerada como consciência atenta à humanidade presente em cada pessoa, enseja uma ética correspondente, a ética fraterna, cujos reflexos políticos incidem numa determinada racionalidade prática, esta, sempre contingente, a enfrentar prudencial e dialeticamente os diversos fatores de interesse da comunidade, que por vezes a aflige de sobressalto, como no caso atual da pandemia instaurada pela Covid-19.

Objetivou-se oferecer pontos de reflexão extraídos especialmente do aspecto da alteridade como acesso à lei natural que se perfaz na experiência prática da fraternidade nas relações interpessoais. Como fator relevante para esta prática, é urgente a construção de um ethos fomentador deste fim, o que se dá por meio da política - não como política formal e 
instrumental, mas como um agir em conjunto. No sentido deste argumento, oportuno defrontar a lei natural ao agir fraterno para servir de horizonte à análise prudencial da prática política, percebendo como a lei natural manifesta por meio da razão, da natureza humana e especialmente da alteridade, possuem conexões atuais, cognoscíveis e realizáveis.

a) Da manifestação da lei natural enquanto razão cujo bem é a verdade, decorre que todo o conhecimento tenha o lastro de instrumento de fraternidade como busca genuína da própria humanidade e de orientação sobre como agir humanamente. Por consequência, informações falsas ou enxertadas de viés ideológico representam a negação do primado do ser humano enquanto ser que dialoga, pois retira do debate a verdade dos fatos sobre os quais a deliberação dialética assentaria sua pauta. O debate político, não raro, reduz-se a meras opiniões retóricas, obstruindo a possibilidade de um verdadeiro consenso e contamina as opções prudenciais acerca das medidas a serem tomadas no campo político, desorientando as ações morais dos indivíduos enquanto membros da comunidade para combater um mal comum. Aqui cabe nomear como possibilidade de ação fraterna, o empenho científico e a responsável divulgação dos dados e informações à população pelos meios de comunicação, bem como o olhar criterioso dos cidadãos acerca das fontes das informações antes de propagá-las pelas redes sociais e demais meios de comunicação privada.

b) Enquanto obediência à natureza humana, cabe dizer que a preservação da vida exige apropriada urgência, sendo a vida um bem da comunidade. A eventual restrição à liberdade de ir e vir é norteada pelo senso de uma liberdade vinculada ao bem comum e por ser assim, a obediência às diretrizes das instituições políticas competentes representa, individualmente, parâmetro de ação moral o que enseja a responsabilidade do isolamento social como uma ação responsável para o bem da vida própria e alheia. Sobre este ponto, cabe também outra reflexão, a de que a obediência às leis, enquanto consenso em torno da verdade (verdade política contingente e mutável - base da racionalidade política), é também uma contribuição à ordem democrática a vencer eventual opinião individual em contrário, em respeito ao consenso.

c) Por fim, no que toca à alteridade, a forma mais premente de manifestação da lei natural, é o agir em direção ao outro que conta. Essa atitude não depende de visões de mundo, de culturas fraternas, nem de argumentos. Esses são aspectos imprescindíveis para a construção de uma sociedade fraterna, mas sob o ângulo da alteridade, o ponto significativo é agir com o outro fraternalmente, considerá-lo igual em responsabilidades e direitos em torno de um fim, ressaltando que nesta caminhada em conjunto, surgem situações nas quais a solidariedade é impreterível. E em tempos de pandemia, no Brasil, resta evidente que embora o vírus revele a igual vulnerabilidade de todos, sobeja ainda mais manifesta a indefensibilidade dos mais 
desfavorecidos (nos mais variados aspectos). Portanto é necessário estar em comunidade e agir em comunidade, removendo diferenças estruturais que separam os indivíduos e indo ao encontro dos outros, de todos os outros.

\section{Considerações finais}

Do ensinamento de Aristóteles de que a excelência em tocar cítara não advém de pensar ou falar a respeito, mas do efetivamente tocá-la, e de igual modo o corajoso não é aquele que discorre eloquentemente sobre a coragem mas quem efetivamente age corajosamente, compreendemos que somos o que praticamos. Portanto, a fraternidade decorre do agir fraternalmente, que se concretiza no fazer-se um com o outro. Por consequência da fraternidade, subentende-se sobrelevar a solidariedade nos relacionamentos, pois, uma vez que a vulnerabilidade demonstrou-se comum a todos, aqueles que já eram vulneráveis passaram a ser os vulneráveis dentre os vulneráveis para os quais a indiferença não poderia representar, em oposição à fraternidade, maior desumanidade.

Neste passo, impende concluir que a fraternidade não só representa o ideal das sociedades contemporâneas pela necessidade de evidenciar o que há de mais humano na humanidade, mas também se apresenta como realidade presente ao alcance da experiência contingencial de todos que se puserem de acordo com as próprias possibilidades e iniciativas fomentar o ethos do encontro. Além das iniciativas de auxílio econômico e apoio psicológico por meio de algumas instituições públicas (não trataremos sobre a adequação do recurso disponível à aferição da necessidade), chama a atenção as espontâneas ações solidárias dos cidadãos voltadas ao combate da pandemia e de seus efeitos sobre os mais necessitados.

Uma ação pertinente para a exemplificação de uma prática fraterna, é o "Laboratório da Cidade" (LdC), uma organização sem fins lucrativos, com sede em Belém, cujo objetivo é pensar uma nova proposta de espaço urbano que ponha em relevo a valorização do ser humano, por meio de práticas solidárias, democráticas e sustentáveis, o que se dá a partir do angariamento de ideias e de práticas de quem se põe disposto colaborar para esse fim. Uma das práticas de combate à pandemia da $\mathrm{LdC}$ foi a mobilização para os cuidados com a higiene da população por meio de instalação de pias para que transeuntes pudessem lavar as mãos, e consistia no trabalho voluntário de quem se dispunha a zelar pela integridade daquela pia que se encontrasse próxima à respectiva residência e que ainda pudesse contabilizar o número de pessoas que a utilizariam durante o tempo de cinco minutos diários. 
Tais iniciativas solidárias e fraternas surgidas no seio da comunidade, ressaltam a criatividade e benevolência como práticas realizáveis e capazes de iluminar esperançosamente os tempos sombrios, máxime onde a redução da vulnerabilidade se faz urgente. Agir fraterno para ser fraterno, ser no plano ético o que consiste o plano ontológico é uma forma de responder à orientação do conhece-te a ti mesmo, inscrita no dintel do templo de Delfos configurando-se como desejo próprio do homem que se singulariza no universo porque busca conhecer a própria humanidade.

\section{REFERÊNCIAS}

AQUINO, Tomás. Suma teológica. v. VII, parte 157. São Paulo: Edições Loyola, 2005.

ARISTÓTELES. Ética a Nicômaco. São Paulo: Edipro, 2014.

BARZOTTO, Luiz Fernando. A Lei Natural como Lei da Humanidade. In: DI LORENZO, Wambert Gomes (org.). Lei natural e ética ambiental: Conferências do Colóquio Internacional Lei Natural e Direito Ambiental IX Colóquio Sul-Americano de Realismo Jurídico. Porto Alegre: Editora Fi, 2017, p. 121-139.

BARZOTTO, Luiz Fernando. Sociedade Fraterna. In: BARZOTTO, Luis Fernando; MÜLLER, Felipe de Matos; COLPO, Luciana Dessanti; BARZOTTO, Luciane Cardoso. (org.). Direito e Fraternidade: outras questões. Porto Alegre: Sapiens, 2018, p. 43-67.

CONSTANT, Benjamin. A liberdade dos antigos comparada à dos modernos. São Paulo: Edipro, 2019.

FINNIS, John. Lei Natural e Direitos Naturais. Tradução: Leila Mendes. São Leopoldo: Unsinos, 2007.

HEIDEGGER, Martin. Introdução à Filosofia. São Paulo: Martins Fontes, 2009.

KENT, Bonnie. A vida moral. In: MCGRADE, A.S. (org.). Filosofia Medieval. São Paulo: Editora Ideias e Letras, 2008. p. 275-300.

LUBICH, Chiara. A fraternidade no Horizonte da Cidade. ABBA - Revista de Cultura, São Paulo,v. 6, n. 3, p. 7-17. 2003.

PRADOS, Alfredo. Ethos y Polis: Bases para una reconstrucción de la filosofia política. São Paulo: EUNSA, 2006. 